\title{
Positive and negative cluster ions from liquid ethanol by fast ion bombardment
}

\author{
$\operatorname{AUTHOR}(\mathrm{S}):$ \\ Kaneda, M.; Shimizu, M.; Hayakawa, T.; Iriki, Y.; \\ Tsuchida, H.; Itoh, A.
}

\section{CITATION:}

Kaneda, M....[et al]. Positive and negative cluster ions from liquid ethanol by fast ion bombardment. JOURNAL OF CHEMICAL PHYSICS 2010, 132(14): 144502.

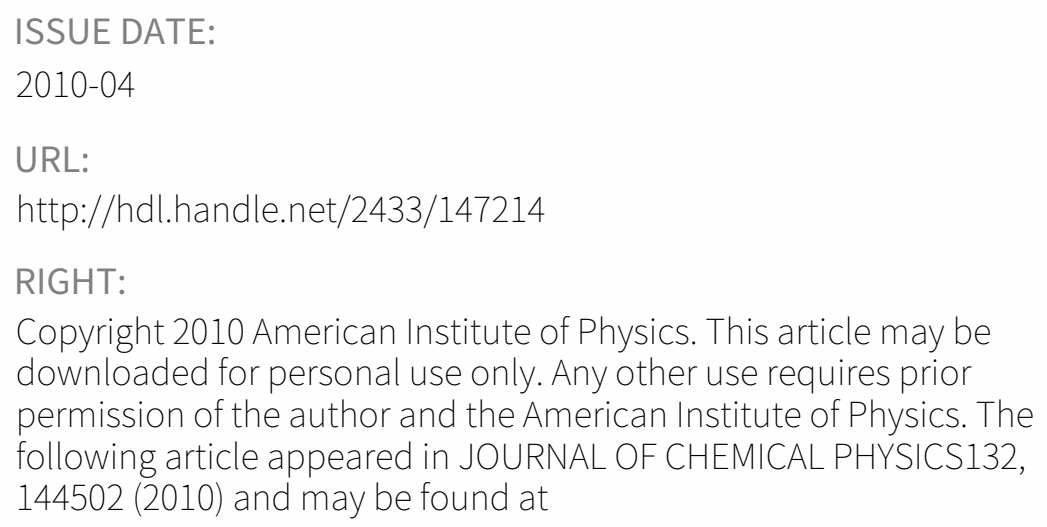




\title{
Positive and negative cluster ions from liquid ethanol by fast ion bombardment
}

\author{
M. Kaneda, ${ }^{1}$ M. Shimizu, ${ }^{1}$ T. Hayakawa, ${ }^{1}$ Y. Iriki, ${ }^{1}$ H. Tsuchida, ${ }^{2}$ and A. Itoh ${ }^{1,2, a)}$ \\ ${ }^{1}$ Department of Nuclear Engineering, Kyoto University, 606-8501 Kyoto, Japan \\ ${ }^{2}$ Quantum Science and Engineering Center, Kyoto University, 611-0011 Uji, Japan
}

(Received 16 March 2009; accepted 28 February 2010; published online 8 April 2010)

\begin{abstract}
Secondary ion mass spectra have been measured for the first time for a liquid ethanol target bombarded by $2.0 \mathrm{MeV} \mathrm{He}{ }^{+}$ions. Positive and negative ion spectra exhibit evidently a series of cluster ions of the forms $\left[(\mathrm{EtOH})_{\mathrm{n}} \mathrm{H}\right]^{+}$and $\left[(\mathrm{EtOH})_{\mathrm{n}}-\mathrm{H}\right]^{-}$, respectively, in addition to light fragment ions from intact parent molecules. It was found that these cluster ions are produced only from liquid phase ethanol. Both positive and negative secondary ion spectra show similar cluster size distributions with almost the same decay slope. We also present for the first time the cluster ion distribution emitted from the liquid at different liquid temperatures. () 2010 American Institute of Physics. [doi:10.1063/1.3367767]
\end{abstract}

\section{INTRODUCTION}

The study of collision interactions of fast charged particles with solid and liquid materials is important to achieve precise understanding of radiation effects induced in matter. ${ }^{1-6}$ In a fast ion impact, electronic excitation of target atoms is the predominant energy transfer process, and it may cause significant ionization in the target, leading to the emission of secondary particles from a target surface known as the sputtering. The sputtering phenomena have been extensively investigated to date by means of time-of-flight secondary ion mass spectrometry (TOF-SIMS). ${ }^{7}$ Nevertheless, it should be pointed out that most TOF-SIMS experiments have been limited to solid targets, and little is known about collision interactions involving liquid targets such as water, aqueous solutions, and alcohols. Investigation using actual liquid materials is undoubtedly essential to obtain direct information about surface and inner structures of liquids, as demonstrated in laser-liquid experiments. ${ }^{8-11}$

For the purpose of full understanding of collision interactions in liquid, we developed recently a new experimental apparatus of accessing volatile liquid targets in vacuum using a technique of liquid molecular beam. ${ }^{12-14}$ New experimental data relevant to stopping power and TOF-SIMS have been obtained for the first time for water, ethanol, and $\mathrm{NaCl}$ solutions. ${ }^{15}$ For instance, in TOF-SIMS measurements for $\mathrm{NaCl}$ solutions, we found that the mass spectra are dominated by a series of cluster ions with intensities varying strongly depending on the concentration of $\mathrm{NaCl}$ in the solutions.

In this work we extend TOF-SIMS investigation to liquid ethanol $\mathrm{C}_{2} \mathrm{H}_{5} \mathrm{OH}$, abbreviated to EtOH hereafter, bombarded by $2.0 \mathrm{MeV} \mathrm{He}{ }^{+}$ions. This is because the liquid ethanol, as one of the most popular polar solvents, has been considerably investigated in radiochemistry by means of radiolysis or high pressure mass spectrometry, and various ionmolecule reactions are well understood. ${ }^{16-24}$ In addition, as

${ }^{\text {a)} E l e c t r o n i c ~ m a i l: ~ i t o h @ n u c l e n g . k y o t o-u . a c . j p . ~}$ the freezing point of ethanol is relatively low $(158.65 \mathrm{~K})$, the liquid molecular beam technique allows one, in principle, to investigate the temperature dependence of radiation effects in a broad range of the liquid temperature. Discussion is given on the formation and emission mechanisms of positive and negative secondary ions. Present results are compared with those obtained by UV lasers ${ }^{10}$ and with solid ethanol data obtained by $\mathrm{keV}$ ion impacts. ${ }^{25,26}$

\section{EXPERIMENT}

The experiment was performed at the Quantum Science and Engineering Center heavy ion accelerator facility of Kyoto University. Figure 1 shows a schematic drawing of our collision chamber consisting of a liquid beam target source, a liquid nitrogen cold trap, and a TOF-SIMS system. A liquid beam target of ethanol (High-performance liquid chromatography grade, 99.5 vol. \%) was produced by essentially the same method as described in previous papers. ${ }^{8-15}$ The liquid beam from an infusion pump designed for a liquid chromatography was injected vertically through a superfine nozzle (MUSASHI Engineering, Inc.) of $20 \mu \mathrm{m}$ in diameter into the center of the collision chamber. The liquid injection

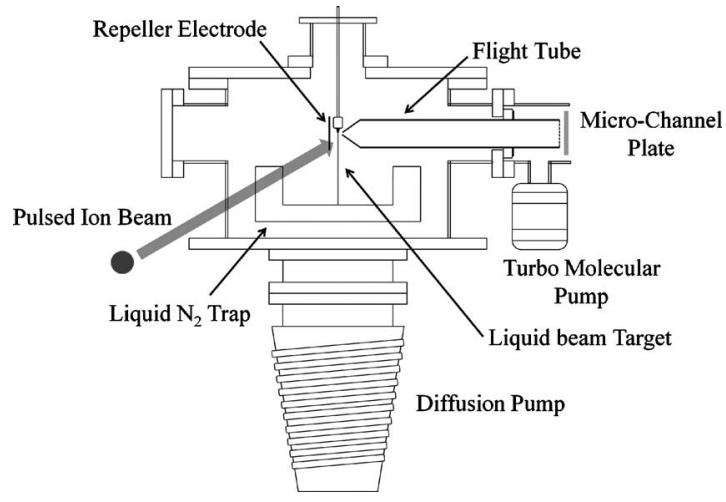

FIG. 1. A schematic of experimental setup consisting of a liquid jet target source, a liquid $\mathrm{N}_{2}$ cold trap, and a TOF mass spectrometry system. The flight tube entrance has an aperture of $1.0 \mathrm{~mm}$ in diameter. 


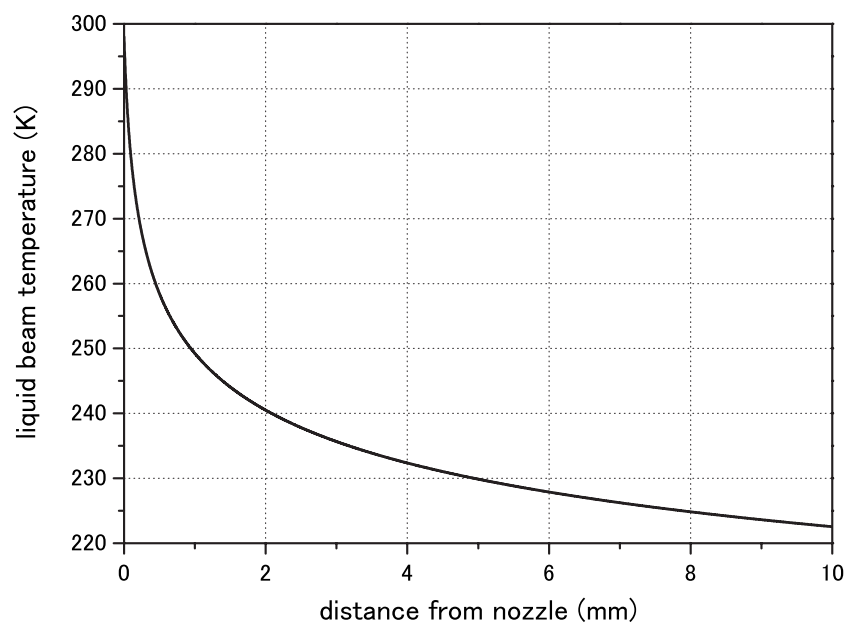

FIG. 2. Variation in liquid ethanol temperature as a function of the distance from a nozzle exit estimated from Ref. 8. The freezing point is $158.65 \mathrm{~K}$ at $1 \mathrm{~atm}$.

system was mounted on a XYZ stage in order to adjust and to keep the TOF alignment. The flow rate of $0.3 \mathrm{ml} / \mathrm{min}$ was used to keep the stability of liquid beam and a good vacuum condition in the collision chamber, which was evacuated by a 1200 l/s diffusion pump. The liquid beam was finally trapped by a liquid nitrogen cold trap positioned at about $6 \mathrm{~cm}$ downstream of the injection nozzle. An ambient pressure during injection of liquid was kept below $1.0 \times 10^{-4}$ Torr.

A beam of $2.0 \mathrm{MeV} \mathrm{He}^{+}$ions from a van de Graaff accelerator was collimated by two two-dimensional slits to a rectangular of about $500 \mu \mathrm{m}$ in vertical and $100 \mu \mathrm{m}$ in horizontal directions. The incident beam was incident on the liquid beam target perpendicularly at a position of $1.0 \mathrm{~mm}$ downstream of the injection nozzle. Before entering the chamber, the incident beam was chopped by an electric deflector to achieve TOF coincidence measurements.

Positive and negative secondary ions were extracted into the TOF spectrometer installed perpendicularly with respect to both beams of $\mathrm{He}^{+}$and the target by applying a static electric field of $1.5 \mathrm{kV} / \mathrm{cm}$. A repeller electrode and a flight tube were separated by $10 \mathrm{~mm}$. After passing through a free flight region of $545 \mathrm{~mm}$ in length, secondary ions were detected by a pair of microchannel plates (MCPs). Applied voltages on the repeller electrode, the drift tube, and the MCP front plate were respectively $0.5,-1.0$, and $-3.0 \mathrm{kV}$ for measurements of positive ions. Those for negative ions were $-0.5,1.0$, and $5.0 \mathrm{kV}$, respectively. In order to reduce undesired background ions originating from evaporated gaseous molecules and to keep a good vacuum circumstance inside the spectrometer, we placed an aperture of $1 \mathrm{~mm}$ in diameter at the entrance of the flight tube. An overall mass resolution, $m / \Delta m$, was about 50 . The $\mathrm{MCP}$ detection efficiency of secondary ions was corrected as described in Ref. 27.

The temperature of the liquid beam was estimated by calculation described in Ref. 8. Results are depicted in Fig. 2 as a function of the distance from the injection nozzle, showing a rapid decrease with increasing distance. Evidently, however, it does not reach the freezing point of $158.65 \mathrm{~K}$ even at $10 \mathrm{~mm}$, implying that the phase transition does not

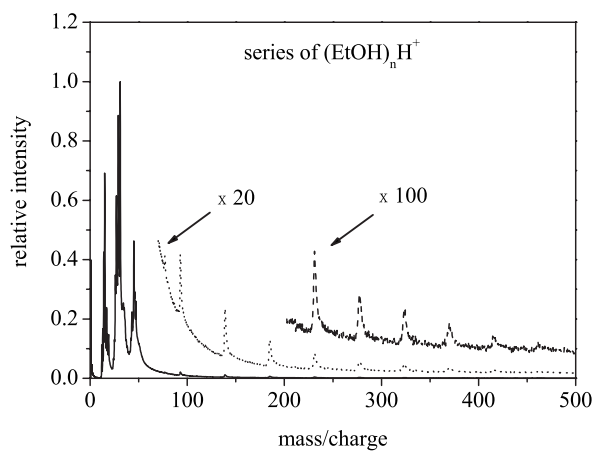

FIG. 3. TOF mass spectrum of positive secondary ions emitted from a liquid ethanol target bombarded by $2.0 \mathrm{MeV} \mathrm{He}$ ions.

take place in the present experiment. Consequently, we could safely investigate secondary ion emission at different liquid temperatures. This was achieved by moving the liquid nozzle vertically, while the relative positions of the TOF axis and the incident ion beam remained unchanged. TOF-SIMS measurements were carried out at the nozzle positions of 1.0, 3.0, and $5.0 \mathrm{~mm}$, corresponding to the temperature of 245,235 , and $228 \mathrm{~K}$, respectively.

\section{RESULTS AND DISCUSSION}

TOF mass spectra of positive and negative secondary ions emitted from liquid ethanol bombarded by $2.0 \mathrm{MeV} \mathrm{He}{ }^{+}$ ions are presented in Figs. 3 and 4, respectively. Both spectra show clearly a series of large cluster ions in addition to fragment ions from ethanol molecules. These cluster ions can be assigned to protonated positive ions of $\left[(\mathrm{EtOH})_{n} \mathrm{H}\right]^{+}$and deprotonated negative ions $\left[(\mathrm{EtOH})_{\mathrm{n}}-\mathrm{H}\right]^{-}$.

Secondary ions may also be produced from gaseous molecules evaporated from liquid as well as from pure liquid phase molecules. Hence, we examined at first the origin of these secondary ions. For this examination, the incident direction of the $\mathrm{He}^{+}$beam was varied horizontally by an electrostatic deflector from $0^{\circ}$ (liquid beam position) toward outside the liquid. At each beam direction we measured the intensity of secondary ions. Note that measurements were performed for positive ions. Results are shown in Fig. 5, where the intensities $I_{i}$ of various ions divided by $I_{31}$ $\left(\mathrm{CH}_{2} \mathrm{OH}^{+}, m / z=31\right)$ are plotted as a function of the deviation of the incident beam from the liquid beam axis. Here, $\mathrm{CH}_{2} \mathrm{OH}^{+}$is the dominant fragment ion produced from de-

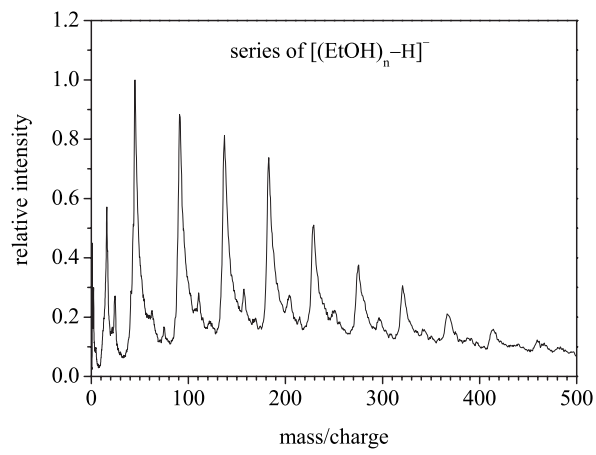

FIG. 4. TOF mass spectrum of negative secondary ions emitted from a liquid ethanol target bombarded by $2.0 \mathrm{MeV} \mathrm{He}{ }^{+}$ions. 


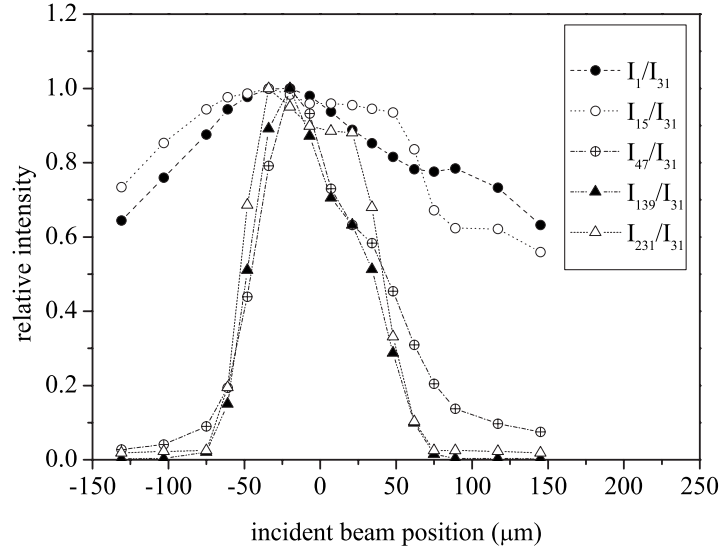

FIG. 5. Intensities of various secondary ions as a function of the deviation of the incident ion beam from the liquid beam axis. Data are normalized to the intensity of $m / z=31$.

composition of ethanol molecules. The subscript $i$ stands for the value of $m / z ; i=1\left(\mathrm{H}^{+}\right), \quad 15\left(\mathrm{CH}_{3}^{+}\right), \quad 47\left(\mathrm{EtOH}_{2}^{+}\right)$, $93\left[(\mathrm{EtOH})_{2} \mathrm{H}^{+}\right]$, and $139\left[(\mathrm{EtOH})_{3} \mathrm{H}^{+}\right]$. All the data are normalized to unity at their peak maxima. Intensity distributions of fragment ions of $\mathrm{H}^{+}$and $\mathrm{CH}_{3}{ }^{+}$are broad, while those of cluster ions are sharply confined within $\pm 100 \mu \mathrm{m}$. Note that the horizontal widths of the incident beam and the liquid target are about 100 and $20 \mu \mathrm{m}$, respectively. From these findings it is concluded that the positive fragment ions originate predominantly from evaporated gaseous molecules, while a series of cluster ions is emitted only from the liquid beam target.

\section{A. Fragment ions}

Figure 6 depicts a lower mass region of positive ions shown in Fig. 3. These light fragment ions provide information about initial physical reactions followed by subsequent physicochemical and chemical reactions, as discussed in the following.

Distinctive peaks at $m / z=1-3,12-15,16-19,24-29$, 28-31, and 42-46 are assigned respectively to $\mathrm{H}_{n}^{+}$(n $=1-3), \mathrm{CH}_{\mathrm{n}}^{+}(\mathrm{n}=0-3), \mathrm{H}_{\mathrm{n}} \mathrm{O}^{+}(\mathrm{n}=0-3), \mathrm{C}_{2} \mathrm{H}_{\mathrm{n}}^{+}(\mathrm{n}=0-5)$, $\mathrm{CH}_{\mathrm{n}} \mathrm{O}^{+}(\mathrm{n}=0-3)$, and $\mathrm{C}_{2} \mathrm{H}_{\mathrm{n}} \mathrm{O}^{+}(\mathrm{n}=2-6)$. Note that the intensity of ethanol ion $\mathrm{CH}_{3} \mathrm{CH}_{2} \mathrm{OH}^{+}$, produced by ionization of a nonbonding oxygen electron, is substantially smaller than its fragment daughter ions. It is known that the ethanol

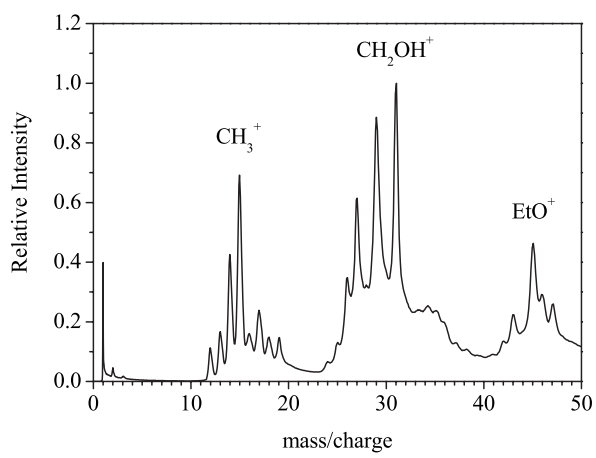

FIG. 6. Lower mass spectrum of positive secondary ions expanded from Fig. 3. ion is stable only when the energy transfer is sufficiently small. ${ }^{16}$ Hence, the present result implies that in fast ion impact, a large amount of energy is transferred during collisions, and various decomposition channels are opened as can be seen in the figure. In addition, $\mathrm{CH}_{3} \mathrm{CH}_{2} \mathrm{OH}^{+}$is a free radical ion and may easily change to $\mathrm{CH}_{3} \mathrm{CH}_{2} \mathrm{O}^{+}$via a H-loss reaction with surrounding molecules.

The relatively strong peak at $m / z=43\left(\mathrm{C}_{2} \mathrm{OH}_{3}{ }^{+}\right)$is produced by $\mathrm{H}_{2}$-loss from $\mathrm{CH}_{3} \mathrm{CHO}^{+} \mathrm{H}$, while the ion $\mathrm{C}_{2} \mathrm{OH}_{4}^{+}$ $(m / z=44)$ produced by $\mathrm{H}_{2}$-loss from an ethanol ion is nearly missing. The same result is reported in other experiments of photoionization and electron impact ionization of gaseous ethanol molecules. ${ }^{17,18}$

Oxionium ions $\mathrm{CH}_{2} \mathrm{OH}^{+}(m / z=31)$ are produced by $\mathrm{C}-\mathrm{C}$ bond breakage of ethanol ions, leading to sequential production of $\mathrm{CH}_{3}$ radicals. The $\mathrm{C}-\mathrm{C}$ bond length of the ethanol ion is known to be about $0.25 \AA$ longer than that of the neutral ethanol molecule. ${ }^{19}$ Consequently, the $\mathrm{C}-\mathrm{C}$ bond breakage reaction is expected to be the most dominant reaction path of ethanol parent ions. A series of $\mathrm{CH}_{\mathrm{n}}{ }^{+}$ions (n $=0-3$ ) of $m / z=12-15$ is also attributed to $\mathrm{C}-\mathrm{C}$ bond breakage of ethanol parent ions.

The ions of $m / z=29$ are attributed to either $\mathrm{C}_{2} \mathrm{H}_{5}{ }^{+}$produced via $\mathrm{C}-\mathrm{O}$ bond breakage or $\mathrm{COH}^{+}$produced via $\mathrm{H}_{2}$-loss from $\mathrm{CH}_{2} \mathrm{CO}^{+} \mathrm{H}$. The ions of $m / z=24-27$ are produced by $\mathrm{C}-\mathrm{O}$ bond breakage and sequential $\mathrm{H}$-loss.

The peaks of $m / z=16-19$ are attributed to $\mathrm{H}_{\mathrm{n}} \mathrm{O}^{+}$(n $=0-3$ ) ions. Among these ions, $\mathrm{H}_{2} \mathrm{O}^{+}$and $\mathrm{H}_{3} \mathrm{O}^{+}$are not formed by simple bond breakage and need bond rearrangement. Similarly, $\mathrm{H}_{2}{ }^{+}$and $\mathrm{H}_{3}{ }^{+}$ions are also produced through bond rearrangement and decomposition. It is noted that the intensity ratio between $\mathrm{H}_{2}{ }^{+}$and $\mathrm{H}_{3}{ }^{+}$is nearly the same as in the electron impact ionization. ${ }^{20}$

The characteristics described above may be typical nature of chemical reactions of singly ionized molecules and seem essentially the same in both gas and liquid phase. In liquid phase, however, ion-molecule and intercluster reactions can also occur, and large cluster ions may also be produced besides small fragment ions. Furthermore, the above reactions occur preferentially along the projectile ion trajectory so that careful analysis of gas-liquid difference of fragment products provides useful information about physics and chemistry inside the ion track.

\section{B. Positive cluster ions}

We discuss here the formation process of positive cluster ions assigned to $\left[(\mathrm{EtOH})_{\mathrm{n}} \mathrm{H}\right]^{+}$. At first the ion $(\mathrm{EtOH})_{1} \mathrm{H}^{+}$ $(m / z=47)$ is known to be produced by the following ultrafast proton transfer reactions: $:^{21}$

$$
\begin{aligned}
& \mathrm{EtOH}^{+}+\mathrm{EtOH} \rightarrow \mathrm{EtOH}_{2}^{+}+\mathrm{EtO}, \\
& (\mathrm{EtOH})_{2}^{+} \rightarrow \mathrm{EtOH}_{2}^{+}+\mathrm{EtO} .
\end{aligned}
$$

The exothermicity of proton transfer reactions leads to further decomposition of $\mathrm{EtOH}_{2}{ }^{+},{ }^{21}$ such as

$$
\mathrm{EtOH}_{2}{ }^{+} \rightarrow \mathrm{H}_{3} \mathrm{O}^{+}+\mathrm{C}_{2} \mathrm{H}_{4},
$$

$\mathrm{EtOH}_{2}^{+} \rightarrow \mathrm{CH}_{2} \mathrm{OH}^{+}+\mathrm{CH}_{4}$, 


$$
\begin{aligned}
& \mathrm{EtOH}_{2}^{+} \rightarrow \mathrm{C}_{2} \mathrm{H}_{5}^{+}+\mathrm{H}_{2} \mathrm{O}, \\
& \mathrm{EtOH}_{2}^{+} \rightarrow \mathrm{C}_{2} \mathrm{H}_{4} \mathrm{OH}^{+}+\mathrm{H}_{2}
\end{aligned}
$$

The larger cluster ions, $(\mathrm{EtOH})_{n} \mathrm{H}^{+}$with $n \geq 2$, are attributed to the following production paths:

$$
\begin{aligned}
& (\mathrm{EtOH})_{\mathrm{n}-1} \mathrm{H}^{+}+\mathrm{EtOH} \rightarrow(\mathrm{EtOH})_{\mathrm{n}} \mathrm{H}^{+}, \\
& (\mathrm{EtOH})_{\mathrm{n}+1}{ }^{+} \rightarrow(\mathrm{EtOH})_{\mathrm{n}} \mathrm{H}^{+}+\mathrm{EtO} .
\end{aligned}
$$

The former is a cluster growing reaction, while the latter is a cluster decomposition reaction. Furthermore, the following evaporation reaction might occur before/after emission into the vacuum:

$$
(\mathrm{EtOH})_{\mathrm{n}+1} \mathrm{H}^{+} \rightarrow(\mathrm{EtOH})_{\mathrm{n}} \mathrm{H}^{+}+\mathrm{EtOH} .
$$

\section{Negative cluster ions}

Negatively charged cluster ions can be assigned to $\left[(\mathrm{EtOH})_{\mathrm{n}}-\mathrm{H}\right]^{-}$. As the primary collisions of energetic particles produce a large number of secondary electrons with energies up to a few tens of $\mathrm{eV},{ }^{28,29}$ these low energy electrons are thought to play an important role in the negative ion formation.

$\mathrm{H}^{-}$and $\mathrm{O}^{-}$ions are known to be produced by dissociative electron attachment (DEA) to condensed ethanol. ${ }^{23}$ In addition, production cross sections of $\mathrm{EtO}^{-}$via DEA to ethanol molecules show several resonant peaks at electron energies from 2 to $8 \mathrm{eV}$. These facts indicate that the negative ions observed in our experiments may be produced through thermalization of secondary electrons inside the liquid. The electron attachment to ethanol clusters possibly produces deprotonated ethanol cluster anions,

$$
e^{-}+(\mathrm{EtOH})_{\mathrm{n}} \rightarrow(\mathrm{EtOH})_{\mathrm{n}-1} \mathrm{EtO}^{-}+\mathrm{H}
$$

In addition, $\mathrm{O}^{-}$anions react with ethanol molecules and produce deprotonated ethanol anions, ${ }^{23}$

$$
\mathrm{O}^{-}+(\mathrm{EtOH})_{\mathrm{n}} \rightarrow(\mathrm{EtOH})_{\mathrm{n}-1} \mathrm{EtO}^{-}+\mathrm{OH}
$$

Fully thermalized electrons are known to form solvated electrons, $e_{\text {solv }}^{-}$, by reorientation of surrounding solvent molecules. Free electrons and solvated electrons react with surrounding molecules and produce $\left[(\mathrm{EtOH})_{\mathrm{n}}-\mathrm{H}\right]^{-}$ions, as follows: ${ }^{24}$

$$
\begin{aligned}
& e_{\mathrm{solv}}{ }^{-}+e_{\mathrm{solv}}{ }^{-} \rightarrow 2 \mathrm{EtO}_{\mathrm{solv}}{ }^{-}+\mathrm{H}_{2}, \\
& e_{\mathrm{solv}}{ }^{-}+\mathrm{EtOH} \rightarrow \mathrm{EtO}_{\mathrm{solv}}{ }^{-}+\mathrm{H} .
\end{aligned}
$$

The evaporative reaction, similar to reaction (9), may also contribute to the formation of negative cluster ions.

\section{Size distribution of cluster ions}

Cluster size (n) distributions of positive and negative ions are shown in Fig. 7 together with other experimental data obtained for liquid ethanol by UV laser irradiation ${ }^{10}$ and for condensed ethanol by $\mathrm{keV}$ ion impacts. ${ }^{25,26}$ Qualitatively to say, the intensity of cluster ions drops rapidly in laser irradiation, while those in $\mathrm{keV}$ ion impacts reveal hump

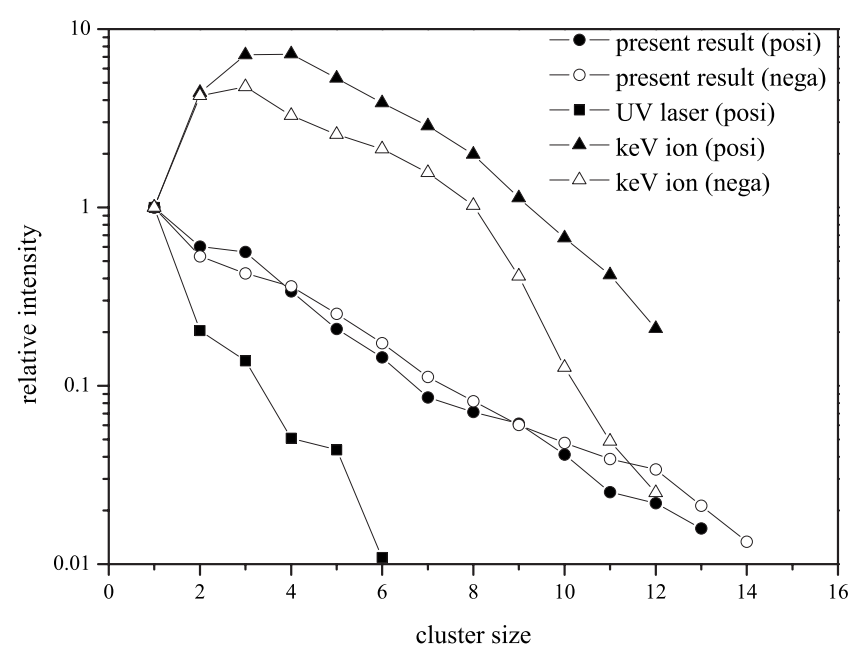

FIG. 7. Cluster size distributions of $\left[(\mathrm{EtOH})_{n} \mathrm{H}\right]^{+}$and $\left[(\mathrm{EtOH})_{n}-\mathrm{H}\right]^{-}$as a function of the cluster size $\mathrm{n}$. Also shown are other experimental results obtained for liquid ethanol by UV laser irradiation (Ref. 10) and solid ethanol by keV ion impacts (Refs. 25 and 26).

structures at about $n=3$ and decrease with increasing $n$. It should be noted that this hump structure may be attributed to a feeding effect from metastable decomposition of larger cluster ions inside a rather long fight tube in the magnet sector type mass spectrometer used in their experiments. ${ }^{25,26}$ On the other hand, present results of both positive and negative ions show nearly the same exponential decay.

Experimental results described above may be interpreted within the framework of standard emission models of secondary particles. For instance, the cluster emission from liquid by laser irradiation is successfully explained by a Coulomb repulsion model, where positive charges are formed inside the target by photoelectron emission. ${ }^{11}$ The size distribution reflects the number of accompanying molecules in the course of Coulomb repulsive emission. Thus, larger cluster ions appear only weakly in their experiments. ${ }^{30}$ In this model, positive and negative ions are thought to be emitted from different cites inside the target. Thus, the size distribution may be different between positive and negative ions.

By contrast, equivalent distribution obtained in the present work implies that other emission model may be valid in $\mathrm{MeV}$ energy collisions. We examined our data with the thermal spike model used frequently for sputtering phenomena caused by energetic ion impacts. ${ }^{31,32}$ In this model, an electron-ion recombination energy is considered as a heat source in the ion track. A part of the electronic excitation energies is converted rapidly to kinetic motion of a molecule through the ultrafast reaction as described in Eq. (1). The remaining energy is also transferred gradually to phonon generation due to nuclear motion and various chemical reactions. Once the thermal equilibrium is achieved, the excess temperature-up distribution in space and time $t$ is given by

$$
\Delta T=\frac{T_{0}}{1+4 \delta t / R_{C}^{2}} \exp \left[-\frac{r^{2}}{R_{C}^{2}+4 \delta t}\right]
$$




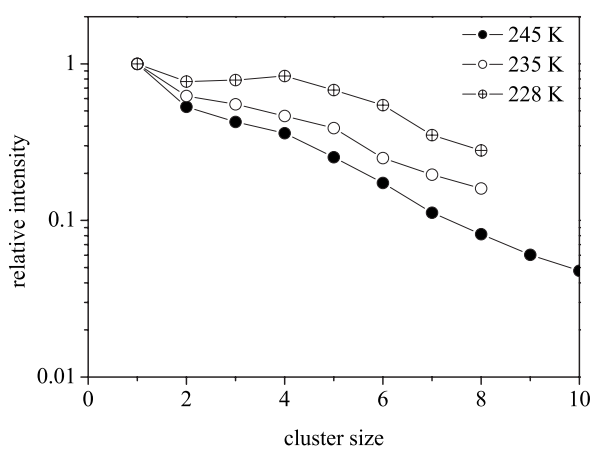

FIG. 8. Temperature dependence of negative cluster ions of $\left[(\mathrm{EtOH})_{\mathrm{n}}\right.$ $-\mathrm{H}]^{-}$plotted as a function of the cluster size $\mathrm{n}$.

$$
T_{0}=\frac{d E / d x}{\pi \rho C_{v} R_{C}^{2}}
$$

where $r$ represents the distance from the ion track center, $T_{0}$ is the initial temperature-up along the track, $\delta$ is the thermal diffusivity, $R_{c}$ is the size of cylindrical ion track. ${ }^{4}$ In collisions of $2 \mathrm{MeV}$ He with liquid ethanol with the ionization energy of $I=10.5 \mathrm{eV}$, we obtain $d E / d x=14 \mathrm{eV} / \AA$ (Ref. 33) and $R_{c} \sim \hbar \pi v / I=19.3 \AA{ }^{3}$ yielding $T_{0} \sim 1000 \mathrm{~K}$. This temperature-up is considerably larger than that before irradiation, and significant thermal evaporation and cluster formation can occur. As the cluster formation may be restricted within this thermally activated region, the cluster size distributions of both positive and negative ions are expected to be equivalent, being consistent with our experimental results. Furthermore, the time duration of the central temperature falling to $T_{0} / 2$ at $r=0$ is obtained as $R_{c}^{2} / 4 \delta=10.9 \mathrm{ps}$, implying that the thermal evaporation occurs on the time scale of picoseconds. ${ }^{34}$

The thermal spike model suggests also that the size distribution is expected to depend only weakly on the liquid temperature. This liquid temperature dependence was measured for negative ions at three different temperatures of 228, 235, and $245 \mathrm{~K}$. As shown in Fig. 8, the size distribution exhibits somewhat large dependence on the liquid temperature. Namely, the intensity of larger cluster ions at highest temperature $245 \mathrm{~K}$ decreases faster than those at lower temperatures. As a possible reason, we speculate that this difference comes from collisional dissociation of large cluster ions during flight in the gas phase target outside the liquid. This is because the vapor pressure becomes higher with increasing temperature, and consequently, the collisional dissociation increases at higher liquid temperatures. On the other hand, if we rely on other emission models such as pressure pulse model and shock wave model, ${ }^{35,36}$ a different conclusion is possibly obtained. Namely, the cluster size distributions with different slopes can certainly be attributed to the temperature dependent structure and stability of clusters in liquids. This is because the thermal equilibrium is not assumed in these models, and the secondary particles are thought to be emitted from the region where the shock wave pressure or the total momentum of impulses overcomes a certain critical value. At present, therefore, the liquid temperature dependence is an open question, and more systematic investigation is needed.

\section{CONCLUSIONS}

By means of a liquid beam technique combined with TOF-SIMS, we performed a detailed investigation of collision interactions between $2.0 \mathrm{MeV} \mathrm{He}{ }^{+}$ions and liquid ethanol. This is the first result of collision-induced secondary ion emission from liquid ethanol.

A series of large cluster ions is observed prominently in mass spectra, and they are certainly emitted only from liquid phase ethanol. On the other hand, light fragment ions from parent molecules are produced predominantly in surrounding gas phase ethanol.

The size distribution of cluster ions decreases exponentially with the same decay slope for both positive and negative ions. The decay slope is found to be smaller than those obtained in UV laser experiments for liquid ethanol. We also present the first preliminary results of liquid temperature dependence of the production of cluster ions. Finally, we stress that the present technique is a promising powerful tool for the study of collision interactions involving liquid materials and various collision reactions occurring on the time scale of picoseconds such as subsequent physicochemical reactions and ion track formation in volatile liquid targets.

\section{ACKNOWLEDGMENTS}

This research is financially supported by JSPS Fellows for Young Scientists under Grant NO. 17-02161 and by a JSPS Grant-in-Aid for Scientific Research (B) under Grant No. 19360427. We gratefully acknowledge Dr. H. Shibata and Messrs. M. Imai, M. Naito, K. Norizawa, and K. Yoshida for valuable discussion and technical supports.

${ }^{1}$ U. Fano, in Charged Particle Tracks in Solids and Liquids, edited by L. H. Gray and G. E. Adams (Institute of Physics, London, 1979), p. 1.

${ }^{2}$ E. M. Bringa and R. E. Johnson, Phys. Rev. Lett. 88, 165501 (2002), and references therein.

${ }^{3}$ I. G. Kaplan and A. M. Miterev, Adv. Chem. Phys. 68, 255 (1980); we used ionization potential $(10.5 \mathrm{eV})$ instead of the lowest transition energy.

${ }^{4}$ A. Mozumder, in Advances in Radiation Chemistry, Vol. 1, edited by M. Burton and J. L. Magee (Wiley-Interscience, NY, 1969), p. 1.

${ }^{5}$ B. Gervais, M. Beuve, G. H. Olivera, and M. E. Galassi, Radiat. Phys. Chem. 75, 493 (2006).

${ }^{6}$ J. Kiefer, New J. Phys. 10, 075004 (2008).

${ }^{7}$ D. P. P. Andrade, H. M. Boechat-Roberty, E. F. da Silveira, S. Pilling, P. Iza, R. Martinez, L. S. Farenzena, M. G. P. Homem, and M. L. M. Eocco, J. Phys. Chem. C 112, 11954 (2008).

${ }^{8}$ M. Faubel, S. Schiemmer, and J. P. Toennies, Z. Phys. D: At., Mol. Clusters 10, 269 (1988).

${ }^{9}$ M. Faubel, B. Steiner, and J. P. Toennies, J. Chem. Phys. 106, 9013 (1997).

${ }^{10}$ F. Mafuné, J. Kohno, and T. Kondow, J. Phys. Chem. 100, 10041 (1996).

${ }^{11}$ J. Kohno, F. Mafuné, and T. Kondow, J. Phys. Chem. A 104, 243 (2000).

${ }^{12}$ A. Itoh, M. Kaneda, S. Satoh, K. Ishii, and H. Tsuchida, Nucl. Instrum. Methods Phys. Res. B 245, 76 (2006).

${ }^{13}$ M. Kaneda, S. Sato, M. Shimizu, Z. He, K. Ishii, H. Tsuchida, and A. Itoh, Nucl. Instrum. Methods Phys. Res. B 256, 97 (2007).

${ }^{14}$ M. Shimizu, M. Kaneda, T. Hayakawa, H. Tsuchida, , and A. Itoh, Nucl. Instrum. Methods Phys. Res. B 267, 2667 (2009).

${ }^{15}$ M. Kaneda, M. Shimizu, T. Hayakawa, A. Nishimura, Y. Iriki, H. Tsuchida, M. Imai, H. Shibata, and A. Itoh, Nucl. Instrum. Methods Phys. Res. B 267, 908 (2009).

${ }^{16}$ H. von Koch and E. Lindholm, Ark. Fys. 19, 123 (1960).

${ }^{17}$ S. Yang, S. M. Brereton, M. D. Wheeler, and A. M. Ellis, Phys. Chem. Chem. Phys. 7, 4082 (2005)

${ }^{18}$ V. Sharma and B. Bapat, J. Chem. Phys. 125, 044305 (2006).

${ }^{19}$ H.-F. Lu, F.-Y. Li, K. Nagaya, M. Hayashi, K. Mishima, and S. H. Lin, J. 
Mol. Struct.: THEOCHEM 761, 159 (2006).

${ }^{20}$ R. Rejoub, C. D. Morton, B. G. Lindsay, and R. F. Stebbings, J. Chem. Phys. 118, 1756 (2003).

${ }^{21}$ L. W. Sieck, F. P. Abramson, and J. H. Futrell, J. Chem. Phys. 45, 2859 (1966).

${ }^{22}$ A. Boatwright, J. Jeffs, and A. J. Stace, J. Phys. Chem. A 111, 7481 (2007).

${ }^{23}$ M. Orzol, I. Martin, J. Kocisek, I. Dabkowska, J. Langer, and E. Illenberger, Phys. Chem. Chem. Phys. 9, 3424 (2007).

${ }^{24}$ D. Jore, B. Champion, N. Kaouadji, J.-P. Jay-Gerin, and C. Ferradini, Radiat. Phys. Chem. 32, 443 (1988).

${ }^{25}$ M. V. Kosevich, G. Criza, O. A. Boryak, V. S. Shelkovsky, and K. Vékey, Rapid Commun. Mass Spectrom. 11, 1411 (1997).

${ }^{26}$ M. V. Kosevich, G. Criza, O. A. Boryak, V. S. Shelkovsky, and K. Vékey, J. Mass Spectrom. 33, 843 (1998).

${ }^{27}$ A. Itoh, H. Tsuchida, T. Majima, and N. Imanishi, Phys. Rev. A 59, 4428 (1999)
${ }^{28}$ J. H. Miller and A. E. S. Green, Radiat. Res. 54, 343 (1973).

${ }^{29}$ C. Champion, O. Boudrioua, C. Dal Cappello, Y. Sato, and D. Ohsawa, Phys. Rev. A 75, 032724 (2007).

${ }^{30}$ G. A. Grieves, N. Petrik, J. Herring-Captain, B. Olanrewaju, A. Aleksandrov, R. G. Tonkyn, S. A. Barlow, G. A. Kimmel, and T. M. Orland, J. Phys. Chem. C 112, 8359 (2008).

${ }^{31}$ R. E. Johnson and W. L. Brown, Nucl. Instrum. Methods Phys. Res. 198, 103 (1982).

${ }^{32}$ P. Sigmund, Appl. Phys. Lett. 25, 169 (1974).

${ }^{33}$ J. F. Ziegler, SRIM2008, available from http://www.srim.org.

${ }^{34}$ R. Kelly, A. Miotello, B. Braren, A. Gupta, and K. Casey, Nucl. Instrum. Methods Phys. Res. B 65, 187 (1992).

${ }^{35}$ L. S. Bitensky and E. S. Parilis, Nucl. Instrum. Methods Phys. Res. B 21, 26 (1987).

${ }^{36}$ R. E. Johnson, B. U. R. Sundqvist, A. Hedin, and D. Fenyo, Phys. Rev. B 40, 49 (1989). 